\title{
Black Box of Interpreting: Hidden under Your Nose? A Study of Shift as the Product of Black Box Based on Tag Gameshow of Youtube
}

\author{
Sebastian Karsten \& Siegfrieda A. S. Mursita Putri \\ Avaritian14@gmail.com \& siegfrieda@ukrida.ac.id \\ Faculty of Humanities and Social Sciences, Universitas Kristen Krida Wacana
}

\begin{abstract}
Translating according to Nida is more about the understanding the concept of translation, in this study the main aims is that to dive deeper into the art of interpretation, another branch of translation. According to Hudson, (2005) Translation as for most people know, is an act of changing Source Language and deliver it into Target Language, so that people who are not a native to it, might understand the point of information itself. Translation and interpretation holds a lot of mysteries, this is the fact that triggers this study to be conducted. This study observes one of Interpretation product made from black box.
\end{abstract}

The black box theory produced by Englund Dimitrova \& Tiselius (2016) is investigated in this study. It also applies interpreting shift proposed by Catford (1965) as the indicators and the products or result of the occurrence of black box and also combined with the techniques applied by the interpreter. The data were fifteen videos from Tara Arts Game Indonesia YouTube channel. The source language from the conversation inside the game and interpreting version were analyzed and then classified into three major classes of shifts to prove the indication that shift is a product of black box. This was a mixed quantitative and qualitative study and also a primary research. The result of this research is that the black box phenomenon is real, triggered by working memory and adjustment as proposed by Baddeley \& Hitch (1974). Meanwhile, the major types of shift found are unit shift, level shift, form 3 and omission.

Keywords: Black Box, Shift, Working Memory

\section{Introduction}

This study is conducted because of the black box phenomenon and the products of black box of itself. Also, this study aims to discover the techniques used by the interpreters while they are doing their job and when this phenomenon is occurring. This is important because to know the product and occurrence of black box, real life interpreting process should be analyzed, that is why the object of this study are chosen. Talking about changes in translation, especially interpretation, makes a big difference in the aspects itself, either in cultural, socio-lingual aspect, even manners, and so on. The product of changes and the cause of changes are described into the paragraphs below

This study has been directly pointed specifically to the Tara Arts Game Show; because they have uploaded their footage on YouTube. This is done considering the process to discover black box requires a lot of repetition to detect what is happening on the spot. So, using the play, pause, and rewind of YouTube, it is possible to detect the phenomenon itself. TAG Game show parties also provide a supportive source in this case, such as a lot of videos that can be a good use 
for this study and live stream while they are playing. This is beneficial because by monitoring them, this study may observe more on their behavioral pattern and the shapes of black box. The next paragraphs is more about describing the methods chosen for this study.

\section{Methods}

The study is qualitative and quantitative study. This is also a primary research. The data chosen were fifteen YouTube videos from Tara Arts Game Indonesia YouTube channel. Tara Arts Game Indonesia YouTube channel is an Indonesian gaming channel. This study chose fifteen videos because it was $10 \%$ of all videos published in the channel, the types of the video were walkthrough, since walkthrough is an informative type of video and it involves a lot of information sharing from SL to TL. The source language and interpreting result were aligned in a table and analyzed in terms of the shift and techniques applied by the interpreter

\section{Findings on Major Shift}

The major shift found as the product of black box in this study is presented in the form of tables, first the findings started on the Category Shift: Unit Shift. Based on the findings, the study wants to show the occurrences of black box in the shape of Unit Shift. Most of them are changing the word rank from phrase to ordinary words, not only that any word rank changes are still counted as unit shift. Something that we all need to keep in mind is that this analysis is based on the study current abilities to decipher and was helped by the theories coined by the experts.

Table 1. Finding of Unit Shift

\begin{tabular}{|c|l|l|c|}
\hline Minutes of Finding & \multicolumn{1}{|c|}{ SL } & \multicolumn{1}{|c|}{ TL } & Form of Black box \\
\hline Minute $5: 22$ of $42: 43$ & $\begin{array}{l}\text { Why are you being so } \\
\text { discreet? }\end{array}$ & $\begin{array}{l}\text { Kenapa lu bisik-bisik } \\
\text { gini sih? }\end{array}$ & Unit Shift \\
\hline
\end{tabular}

Based on the findings that this study found this occurrence is a unit shift because, the shift from discreet, which according to Macmillan dictionary is an Adjective, but when the word was interpreted by the interpreter, the translation result is Bisik-bisik which is a Verb according to KBBI (Kamus Besar Bahasa Indonesia). the changes from adjective to noun is still counted as Unit shift. The next form of black box presented below is the level shift: form 3 .

\section{Level Shift: Form 3}

Table 2. Findings of Level Shift: Form 3

\begin{tabular}{|l|l|l|c|}
\hline Minutes of Meeting & \multicolumn{1}{|c|}{ SL } & \multicolumn{1}{c|}{ TL } & Form of Black box \\
\hline Minute 6:03 of 32:41 & $\begin{array}{l}\text { I'm Medjay to no } \\
\text { Pharaoh }\end{array}$ & $\begin{array}{l}\text { Gua bukan siapa- } \\
\text { siapanya Pharaoh! }\end{array}$ & Level Shifts. \\
\hline
\end{tabular}

Proceeding next to the second shift major that are found within this study, level shift: form 3 , table 2 is presented to show the findings of this type of shift. As the result shown in the table above, the interpreter summarizes the conversation using the Level Shift: Form 3, where the literal translation is available but the interpreter does not use that option. Rather than translating the text according to the rule of TL, the interpreter uses expression in the TL to fill the gap where the correct word is not available in the interpretation that he made. The changes are from "no Pharaoh" to "bukan siapa-siapanya Pharaoh." does not fit to each other, that is why the study classified this occurrence as Level 
Shift: Form 3.and SL is related and make sense, and is different than the previous interpretation made. The last major shift found on this study is Optional Shift: Omission, the paragraphs below contains the complete description for it.

\section{Optional Shift: Omission}

Table 3. Findings of Optional Shifts: Omission

\begin{tabular}{|l|l|l|l|}
\hline \multicolumn{1}{|c|}{ Findings } & \multicolumn{1}{|c|}{ SL } & \multicolumn{1}{c|}{ TL } & Form of Black box \\
\hline $\begin{array}{l}\text { Minute 18:09 of } \\
32: 41\end{array}$ & $\begin{array}{l}\text { It's been months. Look at } \\
\text { that beard! }\end{array}$ & ... Liat jenggot lu tuh! & $\begin{array}{l}\text { Optional Shifts: } \\
\text { Omission. }\end{array}$ \\
\hline
\end{tabular}

The third major and most seen shifts in this study is omission, these ideas that are coined by Toury were differentiated into 3 types, there are 5 sub types for type A-shifts, also there are 2 sub-types for R-type shift and 1 sub-type for type C-Shift. This shift is optional and was done in a conscious state of mind by the interpreter. Omission occurs due to the summarization done by the interpreter to chase and pursue the translation from SL to TL. Some of the findings are presented along with the transcription.

As the transcription shows, the interpretation made is not complete, it is based on the way the interpreter receives the whole message from SL, if the interpreter only receives half of the information, then he will interpret based on what he knows only. Another point of view that this study concludes that is that the interpreter willingly does the omission to make the viewer imagine the situation and to picture the interpretation based on their knowledge.

This is supported by audio-visual aid, where the interpreting take place in the same moment as the game play occurs. A lot of aspect affects this kind of shift, such as explication, elaboration, and repetition. The explanation for the strategy applied by the interpreter is described below.

\section{Strategies Applied}

As the sub-chapter implies, the study describes the types of strategy that the interpreter applies along the process of interpreting. First and foremost, the usage of summarization. Here, summarization means that the interpreter is finding a way to grasp the main idea of SL and translate it into TL. This measure was chosen because it is time effective and rather than translating it word by word, the interpreter translates the in-game conversation into an acceptable and understandable TL. Changes do occur but, then again, the main message that is in SL manages to be transferred well into TL version. Below the study presents some of the examples that are related to this strategy and are written in SL-TL format.

1) SL: Yes! That is me... and no! I am not. I only had two or ten beers.

TL: Gua cuman minum 10 bir (bodo lah). (v5. 12:12 / 42:28)

This is the example that this study manages to get from the in-game conversation, here the interpreter tries to summarize the TL but, in a way, that is acceptable in SL version without omitting to much the lesser information such as, bottle of beers and the subject itself. This measure is the basic of the most occurrences that happens and are applied by the interpreter. Please provide a connecting sentence here before transitioning to another idea.

2) SL: What is this Gods forsaken place? TL: Tempat apa ini (katanya)? (v14. 6:24 / 31:54)

Same as before, the bracketed word shows that the interpreter tries to clarify the points delivered from SL to TL. This measure was taken in order to clarify and replace the word "forsaken" that was omitted before. It leaves the viewers to grasp the ideas of 
omitted word through the short explanation and in-game footage that occurs on the set, itself.

The next strategies that the interpreter applies is addition of information and thinkaloud strategies, this is the technique that the interpreter applies when he faces difficulty when interpreting and also when he needs to explain more on the conversation to the viewers so that the message becomes clearer and understandable. The study presents example on how this strategy applied by the interpreter below.

3) SL: The scarab preys upon the weak; he is no threat to me

TL: Scarab tuh cuman iniin orang-orang lemah (katanya)...

(v8. 11:26/48:31)

Looking at the bracketed words, this is the way applied by the interpreter to explain to the viewer the important points that he could not translate before. As for the think aloud strategies, this is the strategies that the interpreter uses when he is lost between the interpreting processes. Therefore the techniques that are used by the interpreter are usually stating the condition he's facing to the viewer such as, "aduh guys, gua gak ngerti nih.", " duh susah bener bahasanya."," maap-maap nih kalau ada yang gak ngerti yah." By looking at the examples given, the interpreter uses think aloud strategies to express what he is facing or feeling at the time of interpreting. This is important to be applied because it gives more information on the difficulties that the interpreter faced. This strategy also gives more details on the state that the interpreter considers.

\section{Conclusion}

The conclusion from the problems that this study observes is the theories coined by experts and what Diwantara applied in his videos is the same. Parts of the transferring from SL to TL and the process match each other's, due to the difference language some of the aspects shifted each other, the interpreter did practice the theories that were coined by the experts. The tendency that were applied by the interpreter also matches with the description and examples provided by the experts. There are differences because the observation is in the range of this study current knowledge aided with the understanding given by the experts and also the Shift can be interpreted differently by each person.

More onto the strategies applied and chosen by the interpreter such as, think-aloud strategies and technique of adjustment were also applied by the interpreters. Using the concept of understanding between SL and TL the interpreter manages to deliver the ideas to the viewers and it is noticeable for this study to observe more the interpreter's behavior when interpreting.

Think-aloud strategies were used to deliver the obstacles and challenges that the interpreter faced when he is interpreting. By observing at this behavior, the study manages to decide that the tendency of think-aloud strategy usage is when the interpreter face an SL that are untranslatable by him, either he changes the untranslatable words caused by explicitness or harsh language that doesn't met the standards and requirements or to provide another understanding through his gestures and expression.

\section{References}

Arnett, K., Mady, C., \& Muilenburg, L. "Theory and Practice in Language Studies". Academypublisher.Com. .Web. 4(3). https://doi.org/10.4304/tpls.3.1.1-6

Baddeley, A. D., \& Hitch, G. "Working memory". The Psychology of Learning andMotivation. 1974. Web. 47-89.

Catford, J. C. "A Linguistic Theory of Translation".Language and LanguageLearning. Web. Theories of Translation. 1965. 
Dimitrova, B. E., \& Tiselius, E. (2015). Invisible Process? Opening the Black Box of the, (October).

Web.https://doi.org/10.13140/RG.2.1.1 495.3681.1-4.

Englund Dimitrova, B., \& Tiselius, E. "Cognitive aspects of community interpreting". Toward a process model. 2016. Journal. 195-214.

Logie, R. H., \& Cowan, N. "Perspectives on working memory: introduction to the special issue" Memory and Cognition, 43(3),

Web. https://doi.org/10.3758/s13421015-0510-x. 2015. 315-324

Timarova, S. "Working memory and simultaneous interpreting". Translation and Its Others. Selected Papers of the CETRA Research Seminar in Translation Studies 2007, Journal. 2007. 1-28. 